\title{
Cutaneous Leishmaniasis Outbreak Investigation in Hajjah Governorate, Yemen, in 2018: Case-Control Study
}

\author{
Abdulkareem Ali Nassar ${ }^{1}$, MPH; Mahmood Hasan Abdelrazzaq ${ }^{2}$, MD; Ali Hamoud Almahaqri ${ }^{3}$, MCM; Mohammed \\ Abdullah Al-Amad ${ }^{4}$, MPH; Abulwahed Abduljabbar Al Serouri ${ }^{4}$, PhD; Yousef Saleh Khader ${ }^{5}, \mathrm{ScD}$

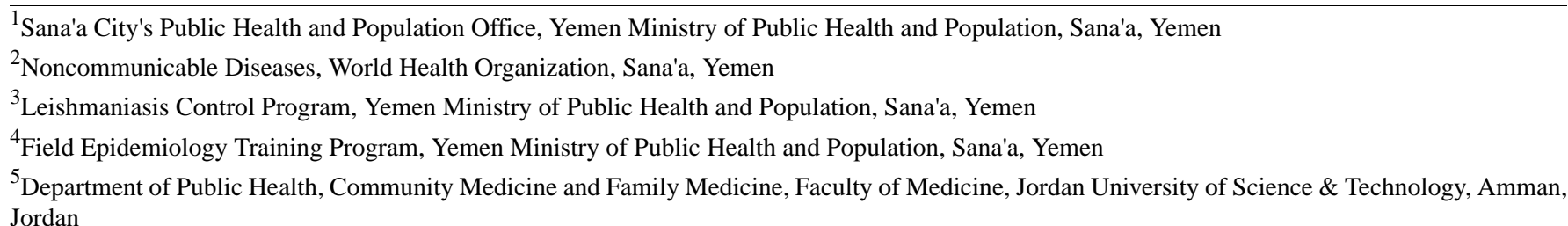 \\ Jordan
}

\section{Corresponding Author:}

Abdulkareem Ali Nassar, MPH

Sana'a City's Public Health and Population Office

Yemen Ministry of Public Health and Population

Al-Thawra District

Sana'a

Yemen

Phone: 967777228977

Email: abdulkareemnassar@gmail.com

\section{Abstract}

Background: Cutaneous leishmaniasis (CL) is endemic in Yemen. About 4440 cases were reported in 2019. On July 23, 2018, a Hajjah governorate surveillance officer notified the Ministry of Public Health and Population about an increase in the number of CL cases in Bani-Oshb, Kuhlan district, Hajjah governorate. On July 24, 2018, Yemen Field Epidemiology Training Program sent a team to perform an investigation.

Objective: We aimed to describe a CL outbreak in Hajjah governorate and determine its risk factors.

Methods: A descriptive study and case-control study (1:1 ratio) were conducted. Cases included people who met the suspected or confirmed case definition of the World Health Organization and lived in Bani-Oshb subdistrict during the period from August 2017 to July 2018. Controls included people living for at least 1 year in Bani-Oshb without new or old skin lesions. Crude odds ratios (cORs) and adjusted odds ratios (aORs) with 95\% CI were used to test the significance of associations.

Results: We identified 30 CL cases. Among the 30 patients, 7 (23\%) were younger than 5 years, $17(57 \%)$ were 5 to 14 years, $17(57 \%)$ were females, and $23(77 \%)$ had one lesion. The attack rate was 7 per 1000 population in the age group <15 years and 1 per 1000 population in the age group $\geq 15$ years. On bivariate analysis, the following factors were significantly associated with CL: female gender (cOR 5.2, 95\% CI 1.7-16.5), malnutrition (cOR 5.2, 95\% CI 1.7-16.5), not using a bed net (cOR 14.5, 95\% CI 1.7-122.4), poor house lighting (cOR 6.4, 95\% CI 2.1-19.7), poor house hygiene (cOR 11.2, 95\% CI 3.1-40.7), poor sanitation (cOR 14.5, 95\% CI 1.7-122.4), living in houses without window nets (cOR 5.2, 95\% CI 1.3-21.2), plantation around the house (cOR 6.5, 95\% CI 2.1-20.5), animal barn inside or close to the house (cOR 9.3, 95\% CI 1.9-46.7), raising animals (cOR 8.1, 95\% CI 1.6-40.7), and having animal dung in or near the house (cOR 6.8, 95\% CI 1.7-27.7). The following risk factors remained significant on multivariate stepwise analysis: female gender (aOR 22.7, 95\% CI 1.6-320.5), malnutrition (aOR 17.2, 95\% CI 1.3-225.8), poor house hygiene (aOR 45.6, 95\% CI 2.5-846.4), plantation around the house (aOR 43.8, 95\% CI 1.9-1009.9), and raising animals (aOR 287.1, 95\% CI 5.4-15205.6).

Conclusions: CL was endemic in Hajjah governorate, and an increase in cases was confirmed. Many individual, housing, and animal related factors were shown to contribute to CL endemicity. Implementation of control measures directed toward altering the factors favoring contact among vectors, reservoirs, and susceptible humans is strongly recommended to control future outbreaks.

(JMIR Public Health Surveill 2021;7(5):e27442) doi: 10.2196/27442 


\section{KEYWORDS}

cutaneous leishmaniasis; outbreak; risk factors; Yemen; Field Epidemiology Training Program

\section{Introduction}

Leishmaniasis is a parasitic disease that is found in parts of the tropics, subtropics, and southern Europe. It is caused by infection with Leishmania parasites, which are spread by the bite of infected sand flies [1,2]. There are different forms of leishmaniasis. The most common form is cutaneous leishmaniasis (CL), which causes skin sores [1]. Most people have CL without any symptoms or signs [3]. People who develop clinical evidence of infection have one or more sores on their skin. The sores can change in size and appearance over time. The sores may start as nodules and may end up as ulcers like a volcano, with a raised edge and central crater [1].

Globally, approximately 700,000 to 1 million new cases and 26,000 to 65,000 deaths occur annually [4,5]. The disease is associated with malnutrition, population displacement, poor housing, a weak immune system, and poor socioeconomic status [4]. In the Eastern Mediterranean Region (EMR), it has been reported in many countries, including Afghanistan, Iran, Iraq, Pakistan, and Syria [4]. The EMR accounts for $70 \%$ of the CL cases worldwide [4].

$\mathrm{CL}$ is endemic in the north-western region of Yemen [6-8]. About 4440 CL cases were reported in 2019 [9]. On July 23, 2018, a Hajjah governorate surveillance officer notified the Ministry of Public Health and Population about an increase in the number of CL cases in Bani-Oshb, Kuhlan district, Hajjah governorate. On July 24, 2018, Yemen Field Epidemiology Training Program sent a team to perform an investigation.

This study aimed to confirm the existence of a CL outbreak in Bani-Oshb, describe the characteristics of CL by person, place, and time, and determine the risk factors of a CL outbreak.

\section{Methods}

\section{Study Area}

This study was conducted in Bani-Oshb subdistrict in Kuhlan Affar district, Hajjah governorate, Yemen. It has a population of 7453 persons (The Immunization Department of The Public Health and Population Office, Kuhlan Affar district, unpublished data, 2017). It has only one health unit, but it is not functional. It is rainy in summer and cold and dry in winter. Most people in Bani-Oshb have cattle and farms. They depend on raising animals and agricultural activities, and their houses are surrounded by farms and trees.

\section{Study Design}

This investigation consisted of descriptive and analytic studies. A line list was developed to collect data, and an active house-to-house search was performed. The World Health Organization (WHO) case definition for CL was used [10]. A suspected case was defined as the presence of clinical signs (skin lesions) without parasitological confirmation of the diagnosis. A confirmed case was defined as the presence of clinical signs with parasitological confirmation of the diagnosis (positive smear or culture from a skin lesion).

A case-control study design was used to determine the risk factors associated with CL (30 cases and 30 controls). Cases included people who met the suspected or confirmed case definition of the WHO and lived in Bani-Oshb subdistrict during the period from August 2017 to July 2018. Controls included people living in the house without any recorded new or old skin lesions among house members according to the household and examination of a medical doctor, and living for at least 1 year in Bani-Oshb without new or old skin lesions.

\section{Data Collection and Diagnosis}

A structured questionnaire was used to collect data on individual, housing, and animal related characteristics. Data were collected on different variables, including age, gender, use of bed nets, house lighting, house hygiene (daily routine of cleaning rooms and disposal of garbage), sanitation (presence of a latrine with safe disposal of human waste), plantation around the house, animal barn inside or close to the house, raising of animals, and animal dung in or near the house. The data on these variables were self-reported by the participants or obtained by observation. One member of the research team collected 22 skin scrapings (small quantities of tissue) from cases. The tissues were directly smeared on glass slides, air dried, and fixed with methanol for a few seconds. After 20 minutes of staining, the slides were washed with water and left to dry in air. Then, the stained smears were sent to the National Central Public Health Laboratories. The laboratory result was considered positive if an amastigote was seen or negative if an amastigote was not seen after 15 minutes of inspection.

\section{Data Analysis}

Data were analyzed using Epi Info version 7.2 [11]. Data were described using percentages. Crude odds ratios (cORs) or adjusted odds ratios (aORs) with $95 \%$ CIs were used to test the significance of associations in bivariate and multivariate stepwise analyses. A $P$ value $<.05$ was considered statistically significant.

\section{Results}

\section{Patient Characteristics}

A total of 30 cases of leishmaniasis were found in Bani-Oshb subdistrict during the period from August 2017 to July 2018. The number of cases started to increase in January 2018 and reached a peak in July 2018 (Figure 1). 
Figure 1. The distribution of cutaneous leishmaniasis cases by time in Bani-Oshb, Hajjah governorate from August 2017 to July 2018 (N=30).

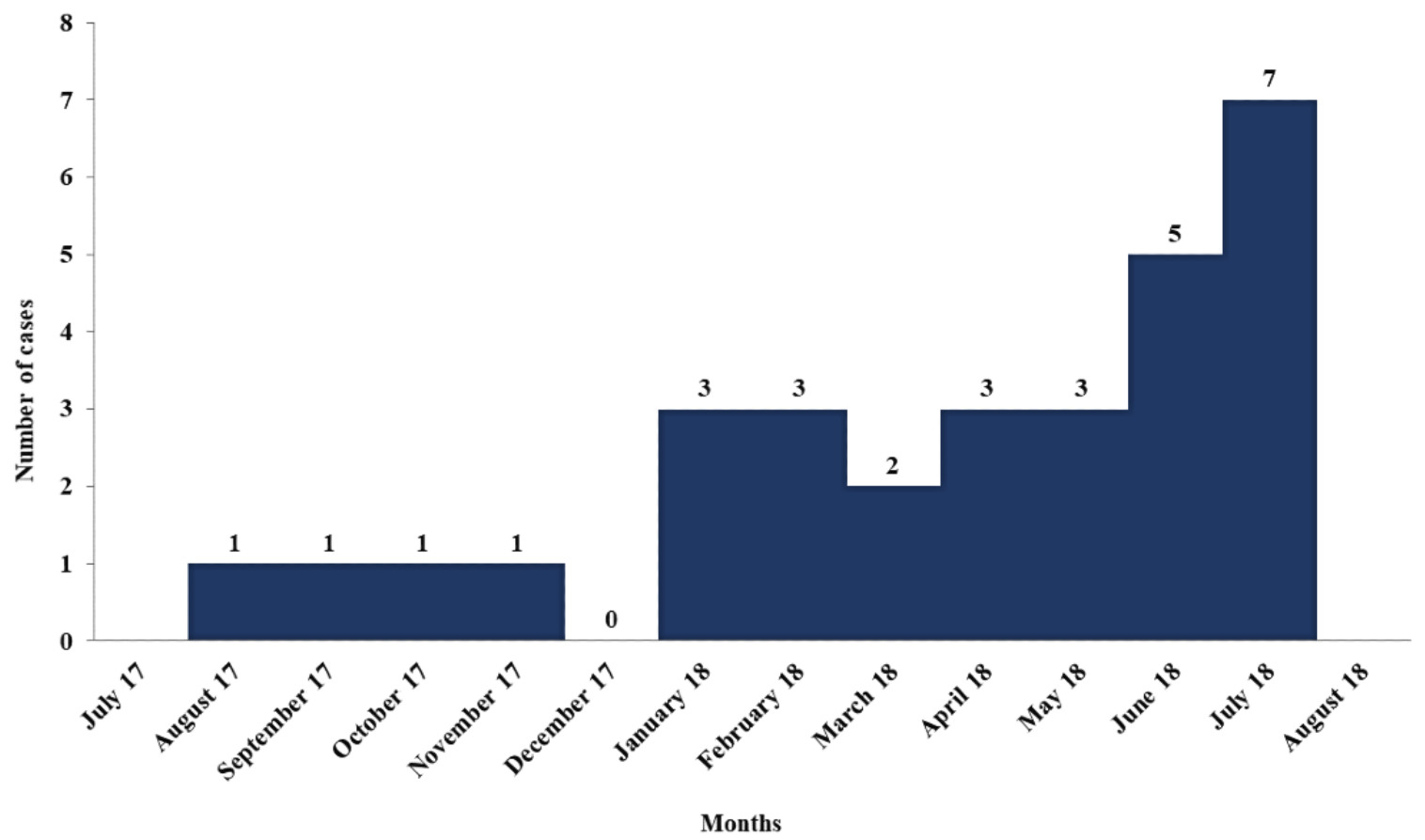

Table 1 shows the characteristics of the CL cases. Of the 30 patients, 7 (23\%) were younger than 5 years, $17(57 \%)$ were aged 5 to 14 years, and $6(20 \%)$ were older than 14 years. Additionally, females represented $17(57 \%)$ cases. Moreover, $23(76 \%)$ patients had one lesion, $4(14 \%)$ had two to three lesions, and $3(10 \%)$ had more than three lesions. The face was the most affected part of the body $(20 / 30,67 \%)$, followed by the lower limbs $(4 / 30,13 \%)$ and upper limbs $(3 / 30,10 \%)$. In $10 \%(3 / 30)$ of cases, both the face and limbs were affected. Bait Rokn and Bait Alfrwi were the most affected villages with 12 $(40 \%)$ cases. The attack rate was 7 per 1000 population in the age group $<15$ years and 1 per 1000 population in the age group $\geq 15$ years. Among 22 skin scraping samples, 21 (96\%) were positive, and leishmaniasis amastigotes were seen. 
Table 1. Characteristics of cutaneous leishmaniasis cases $(\mathrm{N}=30)$.

\begin{tabular}{|c|c|}
\hline Characteristic & Value, $\mathrm{n}(\%)$ \\
\hline \multicolumn{2}{|l|}{ Age (years) } \\
\hline$<5$ & $7(23 \%)$ \\
\hline $5-14$ & $17(57 \%)$ \\
\hline$\geq 15$ & $6(20 \%)$ \\
\hline \multicolumn{2}{|l|}{ Sex } \\
\hline Female & $17(57 \%)$ \\
\hline Male & $13(43 \%)$ \\
\hline \multicolumn{2}{|l|}{ Village of residence } \\
\hline Bait Rokn & $6(20 \%)$ \\
\hline Bait Alfrwi & $6(20 \%)$ \\
\hline Bait Joma'an & $4(13 \%)$ \\
\hline Al Wadi & $3(10 \%)$ \\
\hline Fra'ah & $3(10 \%)$ \\
\hline Al Obal & $2(7 \%)$ \\
\hline Bani Bram & $2(7 \%)$ \\
\hline Bait Za'abl & $2(7 \%)$ \\
\hline Bait Alwali & $1(3 \%)$ \\
\hline Arshan & $1(3 \%)$ \\
\hline \multicolumn{2}{|l|}{ Number of lesions } \\
\hline 1 & $23(76 \%)$ \\
\hline 2 & $2(7 \%)$ \\
\hline 3 & $2(7 \%)$ \\
\hline$>3$ & $3(10 \%)$ \\
\hline \multicolumn{2}{|l|}{ Site of lesions } \\
\hline Face & $20(67 \%)$ \\
\hline Lower limbs & $4(13 \%)$ \\
\hline Upper limbs & $3(10 \%)$ \\
\hline Face and limbs & $3(10 \%)$ \\
\hline
\end{tabular}

\section{Factors Associated With CL}

Table 2 shows the bivariate analysis for associated risk factors of CL. Female gender (cOR 5.2, 95\% CI 1.7-16.5), malnutrition (cOR 5.2, 95\% CI 1.7-16.5), and not using a bed net (cOR 14.5, 95\% CI 1.7-122.4) were associated with increased odds of CL. Poor house lighting (cOR 6.4, 95\% CI 2.1-19.7), poor house hygiene (cOR 11.2, 95\% CI 3.1-40.7), and poor sanitation (cOR $14.5,95 \%$ CI 1.7-122.4) were associated with higher odds of CL. Moreover, other risk factors were identified, including living in houses without window nets (cOR 5.2, 95\% CI
1.3-21.2), plantation around the house (cOR 6.5, 95\% CI 2.1-20.5), animal barn inside or close to the house (cOR 9.3, 95\% CI 1.9-46.7), raising animals (cOR 8.1, 95\% CI 1.6-40.7), and having animal dung in or near the house (cOR 6.8, 95\% CI 1.7-27.7).

The following risk factors remained significant on multivariate stepwise analysis (Table 3): female gender (aOR 22.7, 95\% CI 1.6-320.5), malnutrition (aOR 17.2, 95\% CI 1.3-225.8), poor house hygiene (aOR 45.6, 95\% CI 2.5-846.4), plantation around the house (aOR 43.8, 95\% CI 1.9-1009.9), and raising animals (aOR 287.1, 95\% CI 5.4-15205.6). 
Table 2. Bivariate analysis of associated risk factors of cutaneous leishmaniasis in Bani-Oshb, Hajjah governorate from August 2017 to July 2018.

\begin{tabular}{|c|c|c|c|c|}
\hline Risk factor & Cases $(\mathrm{n}=30), \mathrm{n}(\%)$ & Controls $(\mathrm{n}=30), \mathrm{n}(\%)$ & $\mathrm{cOR}^{\mathrm{a}}(95 \% \mathrm{CI})$ & $P$ value \\
\hline Age (years) & & & $0.8(0.2-2.9)$ & .74 \\
\hline$<15$ & $24(80 \%)$ & $25(83 \%)$ & & \\
\hline$\geq 15$ & $6(20 \%)$ & $5(17 \%)$ & & \\
\hline Sex & & & $5.2(1.7-16.5)$ & .003 \\
\hline Female & $17(57 \%)$ & $6(20 \%)$ & & \\
\hline Male & $13(43 \%)$ & $24(80 \%)$ & & \\
\hline Malnutrition & & & $5.2(1.7-16.5)$ & .003 \\
\hline Yes & $24(80 \%)$ & $13(43 \%)$ & & \\
\hline No & $6(20 \%)$ & $17(57 \%)$ & & \\
\hline Bed net use & & & $14.5(1.7-122.4)$ & .002 \\
\hline Never & $29(97 \%)$ & $20(67 \%)$ & & \\
\hline Use & $1(3 \%)$ & $10(33 \%)$ & & \\
\hline House lighting & & & $6.4(2.1-19.7)$ & $<.001$ \\
\hline Poor & $22(73 \%)$ & $9(30 \%)$ & & \\
\hline Good & $8(27 \%)$ & $21(70 \%)$ & & \\
\hline House hygiene & & & $11.2(3.1-40.7)$ & $<.001$ \\
\hline Poor & $26(87 \%)$ & $11(37 \%)$ & & \\
\hline Good & $4(13 \%)$ & $19(63 \%)$ & & \\
\hline Sanitation & & & $14.5(1.7-122.4)$ & .003 \\
\hline Poor & $29(97 \%)$ & $20(67 \%)$ & & \\
\hline Good & $1(3 \%)$ & $10(33 \%)$ & & \\
\hline Windows of the house & & & $5.2(1.3-21.2)$ & .02 \\
\hline Without net & $27(90 \%)$ & $19(63 \%)$ & & \\
\hline With net & $3(10 \%)$ & $11(37 \%)$ & & \\
\hline Plantation around the house & & & $6.5(2.1-20.5)$ & $<.001$ \\
\hline Yes & $20(67 \%)$ & $7(23 \%)$ & & \\
\hline No & $10(33 \%)$ & $23(77 \%)$ & & \\
\hline Animal barn inside or close to the house & & & $9.3(1.9-46.7)$ & .002 \\
\hline Yes & $28(93 \%)$ & $18(60 \%)$ & & \\
\hline No & $2(7 \%)$ & $12(40 \%)$ & & \\
\hline Raising animals & & & $8.1(1.6-40.7)$ & .004 \\
\hline Yes & $28(93 \%)$ & $19(63 \%)$ & & \\
\hline No & $2(7 \%)$ & $11(37 \%)$ & & \\
\hline Animal dung in or near the house & & & $6.8(1.7-27.7)$ & .003 \\
\hline Yes & $27(90 \%)$ & $17(57 \%)$ & & \\
\hline No & $3(10 \%)$ & $13(43 \%)$ & & \\
\hline
\end{tabular}

a $\mathrm{cOR}$ : crude odds ratio. 
Table 3. Risk factors on multivariate stepwise analysis in Bani-Oshb, Hajjah governorate from August 2017 to July 2018.

\begin{tabular}{|c|c|c|c|c|}
\hline Risk factor & Cases $(\mathrm{n}=30), \mathrm{n}(\%)$ & Controls $(\mathrm{n}=30), \mathrm{n}(\%)$ & $\mathrm{aOR}^{\mathrm{a}}(95 \% \mathrm{CI})$ & $P$ value \\
\hline Sex & & & $22.7(1.6-320.5)$ & .02 \\
\hline Female & $17(57 \%)$ & $6(20 \%)$ & & \\
\hline Male & $13(43 \%)$ & $24(80 \%)$ & & \\
\hline Malnutrition & & & $17.2(1.3-225.8)$ & .03 \\
\hline Yes & $24(80 \%)$ & $13(43 \%)$ & & \\
\hline No & $6(20 \%)$ & $17(57 \%)$ & & \\
\hline House hygiene & & & $45.6(2.5-846.4)$ & .01 \\
\hline Poor & $26(87 \%)$ & $11(37 \%)$ & & \\
\hline Good & $4(13 \%)$ & $19(63 \%)$ & & \\
\hline Plantation around the house & & & $43.8(1.9-1009.9)$ & .02 \\
\hline Yes & $20(67 \%)$ & $7(23 \%)$ & & \\
\hline No & $10(33 \%)$ & $23(77 \%)$ & & \\
\hline Raising animals & & & $287.1(5.4-15205.6)$ & .005 \\
\hline Yes & $28(93 \%)$ & $19(63 \%)$ & & \\
\hline No & $2(7 \%)$ & $11(37 \%)$ & & \\
\hline
\end{tabular}

$\mathrm{a}_{\mathrm{aOR}}$ adjusted odds ratio.

\section{Discussion}

\section{Principal Findings}

A total of 30 cases with leishmaniasis were found in Bani-Oshb subdistrict during the period from August 2017 to July 2018. Our results showed that most CL cases involved patients between the ages of 5 and 14 years and involved females. Additionally, most cases involved one lesion. The face was the most affected part of the body. We also observed that many individual, housing, and animal related factors, such as malnutrition, poor house hygiene, plantation around the house, and raising animals, were significantly associated with CL infection.

The number of cases showed an increase in January and reached a peak in July. This might be due to the rainy season, which is a favorable time for sand fly activity and breeding [8,12]. The age group less than 15 years was the most affected, with an attack rate of 7 per 1000 population. This finding might be explained by the fact that children are usually not aware about how to protect themselves from bites of sand flies. Besides, children spend most of their time outdoors. This finding is similar to the findings in other studies from Taiz and central Yemen governorates, as well as Iran $[8,13,14]$.

Females were more likely to be infected than males. This might be explained by the fact that rural women in Hajjah governorate perform different tasks, including domestic animal care, getting water, and agricultural activities, which increase their probability of exposure to sand fly bites. This finding is consistent with findings in studies from Iran and Lebanon $[14,15]$. However, this finding disagrees with findings in other studies from Lahj, Hajjah, and Amran [6,7,12].
More than three-quarters of CL cases had one lesion. This finding confirms the findings of previous studies from Lahj, Hajjah, Taiz, and Nepal [6-8,16]. In agreement with the findings of other studies $[6,7,12]$, two-thirds of cases had lesions on their faces, and this might be because the face is the most exposed part of the body.

Malnutrition was found to be significantly associated with increased risk of CL infection, which may be due to increased individual susceptibility to infection with CL. Few studies have confirmed the relationship between malnutrition and risk of CL $[17,18]$.

Not using a bed net was significantly associated with increased risk of CL infection. This might be due to the absence of personal protection against the vector. This finding is consistent with the findings of studies from Ethiopia, Waziristan, and Turkey $[5,19,20]$. However, it is not consistent with the findings of other studies from Kenya, Bolivia, Thailand, and Afghanistan [2,21-23].

This investigation indicated that there was an association between CL infection and poor housing characteristics, including poor lighting, house hygiene, and sanitation. These findings might be explained by the fact that such conditions are favorable for the activity and breeding of sand flies. Similar findings have been reported in Amran governorate [12]. Moreover, living in houses without window nets was associated with an increased risk of CL, possibly because of increased exposure to sand flies. One study from Afghanistan did not report a significant association between living in houses without windows and CL [23]. Furthermore, there was an association between plantations around the house and CL. This finding is consistent with the findings of studies from Kenya, Amran, Waziristan, Sri Lanka, and Palestine $[2,12,19,24,25]$ and is not consistent with the 
findings of a study from Thailand [22]. Additionally, having an animal barn inside or close to the house was associated with CL, which has been reported in other studies from Taiz, Amran, and Turkey $[8,12,20]$, but not in a study from Thailand in 2016 [22].

There was an association between animal-related factors and $\mathrm{CL}$ infection. Animals seem to be an important reservoir for maintaining the life cycle of many Leishmania species and transmission of infection. Similar findings were reported in studies from Taiz, Amran, Ethiopia, Turkey, and Palestine $[5,8,12,20,25]$, but not in a study from Thailand [22]. Furthermore, animal dung in or close to the house increased the risk of CL infection because this creates a favorable environment to attract sand flies into human settlements. This finding agreed with the findings of a study from Turkey [20].

However, some of the abovementioned significant risk factors identified in bivariate analysis, which were also reported in previous studies, did not remain significant on multivariate stepwise analysis (eg, bed net use, house lighting, and sanitation). This may be because of the small sample size of this study or because those factors were not risk factors in the studied community.
This study has some limitations related to the study design and sample size. Recall bias might be present owing to the retrospective design of this study. The small sample size is possibly the most important limitation, which generated a wider CI. The study was performed in a subdistrict with mountainous terrain where communities are scattered and difficult to reach, and their work in agricultural activities during the day limited participation in this study. Moreover, difficulty in obtaining eligible controls in this endemic area was the main drawback of enrolling more controls.

\section{Conclusions}

CL was endemic in Hajjah governorate, and an increase in cases was confirmed. Many individual, housing, and animal related factors were shown to contribute to CL endemicity. Implementation of control measures directed toward altering the factors favoring contact among vectors, reservoirs, and susceptible humans, such as malnutrition and plantation around the house, is recommended to control future outbreaks. Further studies focusing on the species of parasites, vectors, and reservoirs are recommended.

\section{Acknowledgments}

The authors would like to acknowledge the Training Programs in Epidemiology and Public Health Interventions Network (TEPHINET) and the Global Health Development|Eastern Mediterranean Public Health Network (GHD|EMPHNET) for their support. We are grateful to Malak Al Sabahi for checking the English language of our manuscript.

\section{Conflicts of Interest}

None declared.

\section{References}

1. About Leishmaniasis. Centers for Disease Control and Prevention. URL: https://www.cdc.gov/parasites/leishmaniasis/ gen info/faqs.html [accessed 2020-03-14]

2. Ngere I, Gufu Boru W, Isack A, Muiruri J, Obonyo M, Matendechero S, et al. Burden and risk factors of cutaneous leishmaniasis in a peri-urban settlement in Kenya, 2016. PLoS One 2020;15(1):e0227697 [FREE Full text] [doi: 10.1371/journal.pone.0227697] [Medline: 31971945]

3. Health Topic: Leishmaniasis. World Health Organization. URL: https://www.who.int/health-topics/leishmaniasis\#tab=tab 1 [accessed 2020-03-14]

4. Fact Sheet: Leishmaniasis. World Health Organization. URL: https://www.who.int/news-room/fact-sheets/detail/leishmaniasis [accessed 2020-03-14]

5. Eshetu B, Mamo H. Cutaneous leishmaniasis in north-central Ethiopia: trend, clinical forms, geographic distribution, and determinants. Trop Med Health 2020;48:39 [FREE Full text] [doi: 10.1186/s41182-020-00231-w] [Medline: 32518497]

6. Muqbil N, Muqbel A. Cutaneous leishmaniasis in Al-Sawalha area, Lahj governorate, Yemen. Micromedicine 2016;4(1):37-42 [FREE Full text]

7. Khatri ML, Haider N, Di Muccio T, Gramiccia M. Cutaneous leishmaniasis in Yemen: clinicoepidemiologic features and a preliminary report on species identification. Int J Dermatol 2006 Jan;45(1):40-45. [doi: 10.1111/j.1365-4632.2004.02588.x] [Medline: 16426374]

8. Asmaa Q, Al-Shamerii S, Al-Tag M, Al-Shamerii A, Li Y, Osman BH. Parasitological and biochemical studies on cutaneous leishmaniasis in Shara'b District, Taiz, Yemen. Ann Clin Microbiol Antimicrob 2017 Jul 04;16(1):47 [FREE Full text] [doi: 10.1186/s12941-017-0224-y] [Medline: 28676088]

9. Leishmaniasis: Status of endemicity of cutaneous leishmaniasis. World Health Organization. 2019. URL: https://apps. who.int/neglected diseases/ntddata/leishmaniasis/leishmaniasis.html [accessed 2020-03-14]

10. Neglected tropical diseases: Cutaneous leishmaniasis factsheet. World Health Organization. URL: http://www.emro.who.int/ neglected-tropical-diseases/information-resources-leishmaniasis/cl-factsheet.html [accessed 2021-05-06]

11. Epi Info. Centers for Disease Control and Prevention. URL: https://www.cdc.gov/epiinfo/index.html [accessed 2021-05-06] 
12. Abdulmogni G, Al-Amad M, Anam L, Banower GM. Outbreak investigation of Cutaneous Leishmania in Yanaha village, Amran governorate, Yemen 2016. National Yemen Field Epidemiology Training Program. 2016. URL: https://tinyurl.com/ mufh7xmc [accessed 2019-05-12]

13. Al-Kamel MA. Leishmaniasis in Yemen: a clinicoepidemiological study of leishmaniasis in central Yemen. Int J Dermatol 2016 Aug;55(8):849-855. [doi: 10.1111/ijd.13041] [Medline: 26547479]

14. Nikouee F, Soltanian M, Babaee F, Motamed-Jahromi M. Cutaneous leishmaniasis: an epidemiological survey in Iran during 2013-2015. JNMS 2017 May 01;4(1):58-62. [doi: 10.18869/acadpub.jnms.4.1.58]

15. Alawieh A, Musharrafieh U, Jaber A, Berry A, Ghosn N, Bizri AR. Revisiting leishmaniasis in the time of war: the Syrian conflict and the Lebanese outbreak. Int J Infect Dis 2014 Dec;29:115-119 [FREE Full text] [doi: 10.1016/j.ijid.2014.04.023] [Medline: 25449245]

16. Ghimire P, Shrestha R, Pandey S, Pokhrel K, Pande R. Cutaneous Leishmaniasis: A Neglected Vector Borne Tropical Disease in Midwestern Region of Nepal. Nepal J Dermatol Venereol \& Leprol 2018 Mar 29;16(1):41-44 [FREE Full text] [doi: 10.3126/njdvl.v16i1.19405]

17. Weigel MM, Armijos RX, Zurita C, Racines J, Reddy A, Mosquera J. Nutritional status and cutaneous leishmaniasis in rural Ecuadorian children. J Trop Pediatr 1995 Feb;41(1):22-28. [doi: 10.1093/tropej/41.1.22] [Medline: 7723125]

18. Castro MDM, Cossio A, Velasco C, Osorio L. Risk factors for therapeutic failure to meglumine antimoniate and miltefosine in adults and children with cutaneous leishmaniasis in Colombia: A cohort study. PLoS Negl Trop Dis 2017

Apr;11(4):e0005515 [FREE Full text] [doi: 10.1371/journal.pntd.0005515] [Medline: 28379954]

19. Rehman I, Saleem M. Outbreak Investigation of Cutaneous Leishmaniasis (CL) in North Waziristan Agency, Federally Administered Tribal Area (FATA) - April 2016. iproc 2018 Mar 29;4(1):e10634 [FREE Full text] [doi: 10.2196/10634]

20. Votýpka J, Kasap OE, Volf P, Kodym P, Alten B. Risk factors for cutaneous leishmaniasis in Cukurova region, Turkey. Trans R Soc Trop Med Hyg 2012 Mar;106(3):186-190. [doi: 10.1016/j.trstmh.2011.12.004] [Medline: 22284721]

21. Eid D, Guzman-Rivero M, Rojas E, Goicolea I, Hurtig A, Illanes D, et al. Risk factors for cutaneous leishmaniasis in the rainforest of Bolivia: a cross-sectional study. Trop Med Health 2018 Apr 17;46(1):9 [FREE Full text] [doi: 10.1186/s41182-018-0089-6] [Medline: 29692654]

22. Manomat J, Leelayoova S, Bualert L, Tan-Ariya P, Siripattanapipong S, Mungthin M, et al. Prevalence and risk factors associated with Leishmania infection in Trang Province, southern Thailand. PLoS Negl Trop Dis 2017 Nov;11(11):e0006095 [FREE Full text] [doi: 10.1371/journal.pntd.0006095] [Medline: 29155831]

23. Reithinger R, Mohsen M, Leslie T. Risk factors for anthroponotic cutaneous Leishmaniasis at the household level in Kabul, Afghanistan. PLoS Negl Trop Dis 2010 Mar 23;4(3):e639 [FREE Full text] [doi: 10.1371/journal.pntd.0000639] [Medline: 20351787]

24. Wijerathna T, Gunathilaka N, Gunawardena K, Rodrigo W. Socioeconomic, demographic and landscape factors associated with cutaneous leishmaniasis in Kurunegala District, Sri Lanka. Parasit Vectors 2020 May 12;13(1):244 [FREE Full text] [doi: 10.1186/s13071-020-04122-1] [Medline: 32398102]

25. Salah I, Davidovitch N, Kotler B. Risk factors of Cutaneous Leishmaniasis (CL) caused by L. tropica: a case-control study in Palestine: Ikram Salah. European Journal of Public Health 2016 Nov 02;26(1):95. [doi: 10.1093/eurpub/ckw166.055]

\section{Abbreviations}

aOR: adjusted odds ratio

cOR: crude odds ratio

CL: cutaneous leishmaniasis

EMR: Eastern Mediterranean Region

WHO: World Health Organization

Edited by M Alyahya, T Sanchez; submitted 25.01.21; peer-reviewed by F Lami, A Sudaryanto; comments to author 28.02.21; revised
version received 30.03.21; accepted 31.03.21; published 14.05.21
Please cite as:
Nassar AA, Abdelrazzaq MH, Almahaqri AH, Al-Amad MA, Al Serouri AA, Khader YS
Cutaneous Leishmaniasis Outbreak Investigation in Hajjah Governorate, Yemen, in 2018: Case-Control Study
JMIR Public Health Surveill 2021;7(5):e27442
URL: https://publichealth.jmir.org/2021/5/e27442
doi: $\underline{10.2196 / 27442}$
PMID:


(C)Abdulkareem Ali Nassar, Mahmood Hasan Abdelrazzaq, Ali Hamoud Almahaqri, Mohammed Abdullah Al-Amad, Abulwahed Abduljabbar Al Serouri, Yousef Saleh Khader. Originally published in JMIR Public Health and Surveillance (https://publichealth.jmir.org), 14.05.2021. This is an open-access article distributed under the terms of the Creative Commons Attribution License (https://creativecommons.org/licenses/by/4.0/), which permits unrestricted use, distribution, and reproduction in any medium, provided the original work, first published in JMIR Public Health and Surveillance, is properly cited. The complete bibliographic information, a link to the original publication on https://publichealth.jmir.org, as well as this copyright and license information must be included. 